Received: November 25, 2017

\title{
Impact of Data Analysis on the Business Administration Education Reform in Teaching Style*
}

\author{
Bai Yang ${ }^{1}$ \\ Chongqing Technology and Business \\ University
}

\author{
Wei Chen ${ }^{2}$ \\ Chongqing Technology and Business \\ University
}

\begin{abstract}
With the innovation development of the science and technology, the human society has stepped into the big data era when it is the teaching demand and future trend to apply and develop the big data in business administration education. Against the backdrop of the big data era, objective analysis of college teaching style reform is the key to determine the relationship between the big data and the business administration education, thus promoting the bilateral common development. This paper firstly introduces the theories about the big data and business administration education, then explains the relationship and action mechanism between these two, and finally explores the the big data's driving force in reform of teaching, learning, evaluation, management, research \& development and service in business administration education. This paper not only ascertains the role of big data in business administration education informationization, but also spurs further synergic development of the big data and university or college education.
\end{abstract}

\section{Keywords}

Big Data $•$ Business Administration Education • Interaction • Reform Driving

\footnotetext{
*The authors acknowledge funding from the postgraduate education reform project of Chongqing (Project No. yjg182029), as well as the contributions from all partners of the mentioned project.

${ }^{1}$ Research Center for Enterprise Management, Chongqing Technology and Business University, Chongqing 400067, China; School of Management, Chongqing Technology and Business University, Chongqing 400067, China. Email: Yangbai@ctbu.edu.cn

${ }^{2}$ Correspondence to: Wei Chen. Research Center for Enterprise Management, Chongqing Technology and Business University, Chongqing 400067, China; School of Management, Chongqing Technology and Business University, Chongqing 400067, China. Email: chenwei@ctbu.edu.cn
}

Citation: Yang, B., Chen, W. (2018). Impact of Data Analysis on the Business Administration Education Reform in Teaching Style. Educational Sciences: Theory \& Practice, 18(5), 2124-2133. http://dx.doi.org/10.12738/estp.2018.1.0608 
With the development of the Internet communication technology and the mobile networks, the network data has been experiencing exponential development since 2010, and the big data era has come with the accumulate of data increasing rate and quantity. People have obtained increasingly more chances to touch and perceive data of various categories from various channels and to exploit its value. The big data has been regarded as "the next recyclable natural resources" of human (Lu, Zhu, Liu, Liu \& Shao 2014).

The big data has been driving the development of various industries in modern society by accelerating industrial innovation or reform. Its application in education is an inevitable future trend and has been promoted around the globe currently (Qin, 2014). It has become the research focus for scholars to study the challenges and social risks that the big data faces in its application in education, to have a correct understanding of the bilateral mutual promotion and inter-conditioning relationship between the big data and business administration education as well as the driving force of the big data in the development of business administration education (Zhang, Li \& Hao, 2015).

This paper aims at studying the influence of the big data on business administration teaching style reform, i.e. the impetus of the big data for the college education concerned with reform of teaching, learning, evaluation, management, scientific research and service, etc. At first this paper makes clear the study object by defining the big data and business administration education, then analyzes comprehensively the interrelation and action mechanism between these two using the method of literature study, case study and comparative analysis (Peng, 2017), and finally summarizes driving force of the big data to the teaching style reform in business administration education. Meanwhile, as the application of the big data in business administration education is still in its primary stage, this paper studies the driving force of the big data to business administration education reform in teaching style by combing theoretic exploration with application so as to avoid transplanting application in this field abroad, thus providing effective guiding to the university education in China.

\section{Elaboration of the core concepts}

\section{Definition and theory of the big data}

Definition of the big data. The big data can be defined in terms of data-set, technical system and thinking pattern. Its valuable information data-set includes not only normal data of the information system, but also data created by social media users (Lazer, Kennedy, King \& Vespignani 2014). In terms of technology, it is the technique to obtain valuable information from the sea of information, including techniques of new data storage, mining, processing, analysis and visualization, etc. In education the most often applied are the techniques for educational data mining, learning analysis, and application in big education platform. In terms of thinking pattern, it is a data technique to recognize and solve problems and a kind of quantified world view and methodology (Costa, 2014). Table 1 shows its definition and application in education.

Characteristics of the big data. The characteristics of the big data can be summarized as $4 \mathrm{~V}$, large-scale (Volume), diversity (Variety), high speed (Velocity), and valuable (Value). The volume means that its unit has been upgraded from GB to TB, then to PB, and even to EB and ZB. Diversity refers to that with the development 
of various mobile internet equipment, the Internet of Things, mobile intelligent equipment, the data has been increasingly abundant in variety. High speed refers to the "one-second rule" in data processing. High-value and low-density refers the disproportion between the number of valuable data and the total number of data (Saude,

Borralho, Feria, Lopes \& Dziawgo, 2014).

Table 1

The Defining Concepts of Big Data

\begin{tabular}{lll}
\hline Angle & \multicolumn{1}{c}{ Description } & \multicolumn{1}{c}{ Application in education } \\
\hline Dataset & $\begin{array}{l}\text { Large data sets, different from the typical } \\
\text { database of data objects, data forms more } \\
\text { diverse and complex relationships }\end{array}$ & $\begin{array}{l}\text { Massive teaching resources (text, video) } \\
\text { and student learning behavior data }\end{array}$ \\
\hline $\begin{array}{l}\text { Technical } \\
\text { system }\end{array}$ & $\begin{array}{l}\text { New data acquisition, data storage, data } \\
\text { analysis, data interpretation and other } \\
\text { technologies }\end{array}$ & $\begin{array}{l}\text { Education Data Mining and Learning } \\
\text { Analysis Technology, Adaptive Learning } \\
\text { System, MOOCs }\end{array}$ \\
\hline $\begin{array}{l}\text { Way of } \\
\text { thinking }\end{array}$ & $\begin{array}{l}\text { Quantify the world view and quantitative } \\
\text { empirical methodologies, the whole sample } \\
\text { of data analysis }\end{array}$ & $\begin{array}{l}\text { Quality of education and evaluation of } \\
\text { thinking and so on }\end{array}$ \\
\hline
\end{tabular}

2.1.3 Theory about the big data. the big data is the embody of information technology in the form of data. Its theory about information technology is as shown in Figure 1.

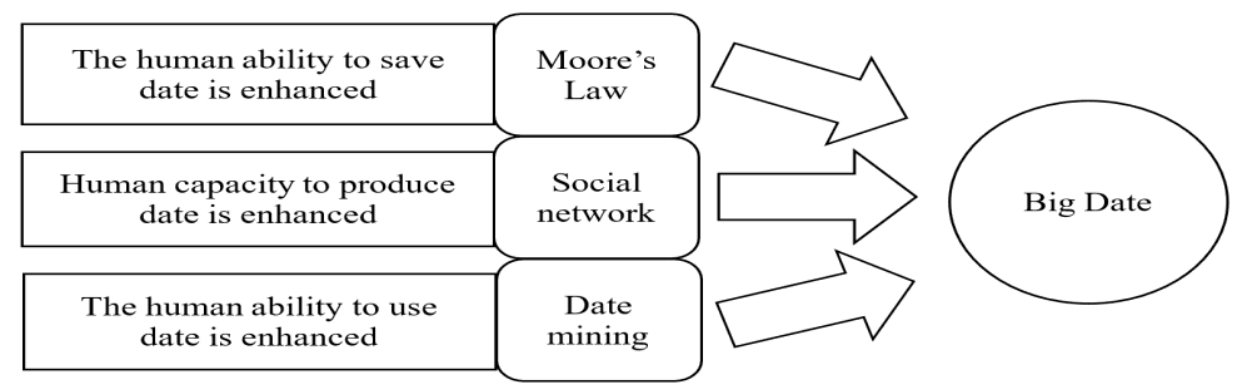

Figure 1. Big data theory of information technology

The Moore's Law reveals the development rule of computer hardware, i.e. with its development, the mass increase of data storage capacity can provide hardware support for the big data. Data mining is like gold mining in the iron mine and mature data mining technique is to search for "high value" key technique from the massive volume of big data. Social media, the social network represented by Facebook, has become an important media for people to output behavior, thinking, and knowledge as well as an important source of the massive data in the big data era after over ten years of development (Brown, Thomas, Merwe \& Dyk, 2008).

\section{Theory about the impact of the big data on the university education}

Modernization of the university education. The higher education, the professional education after the secondary education, is the social activity to train top professional talents. As a kind of activity and a system, it owns the basic education and social functions (Kholin \& Kalugin, 2013). With the transition from traditional to the modern society, the traditional education concept has changed with the social development. External social pressure and internal drive from the modern social university has pushed the college education onto a road of modernized development that aims at meeting the demands for top talents. 
Application of the big data in higher education. The development of the big data in higher education can be divided into three stages: the primary stage, the key exploration stage, and fast development stage.

(1) The primary stage (1990-1997)

During this phase the computer technology was introduced into education innovatively and obtained attention from the academic world. However, as high cost restrained the popularization of the computer in education, its application was still in the primary stage.

(2) The key exploration stage (1997-2008)

The word "big data" appeared the first time in the paper Big Data Processing in the 1998 edition of journal science. Then the big data storage capacity was improved with the emergence of the intelligent system, artificial intelligence system and the digital teaching platform. Meanwhile, the development of the technology in education data mining perfected the big data mining technique, but the potential value of the big data was still not fully exploited.

(3) Fast development Stage (2008 till now)

During this period the concept of big data has been well known gradually to the public and it has been applied deeply into various industries. High attention from the government and education bureau as well as the progress made in education data mining and learning analysis technique has enabled the big data usher in a new era when it is deeply applied in the education (Gusev, Kashfullina \& Nasonov, 2014).

\section{The Interrelation and action mechanism between the big data and university education}

\section{The Relationship between the big data and the university education}

The relation between the big data and business administration education is not a simple one that the big data is applied in the university education. As the university is an organization to train talents, rather than passively letting in the big data, it plays an important role in the development of the big data. Therefore, these two are in a relation of mutual promotion, mutual restraint and common development.

(1) Mutual promotion

The big data provides new teaching methods such as multimedia web-based teaching, remote teaching and computer-aided teaching for the university education, thus promoting the popularization of the university education and breaking down the limitation of time and space. It also provides more convenience and reliable data for the scientific research in the university. On the contrary, the education information system in the university is an important complementary to the big data. Meanwhile, the talents trained by the university are the talent foundation for the improvement of big data technology. So, these two are in a mutual promotion relationship. 
Yang, Chen / Impact of Data Analysis on the Business Administration Education Reform in Teaching Style

(2) Mutual restraint

At present the coverage rate of the university instruction system based on information technology can reach $98 \%$, and that of the information management system can reach $95.3 \%$ while that of the information research system can reach $84.4 \%$. These information platforms produce every day massive data that needs be mined and processed. So the big data processing technology that is still not mature has restrained the development of higher education. Meanwhile, the maturity of the big data processing technique requires professional talents from the higher education, so the efforts made in higher education about the big data determines the training progress of the talents for big data application and processing, i.e. the higher education restrains the development of the big data (Contributor, 2013).

(3) Common development

The relationship of mutual promotion and restraint between big data and higher education decides that these two can only develop together to realize high coupling between each other. These two should strengthen their mutual support in order to keep the pace of common development.

\section{Action Mechanism of the big data in its deep development in higher education}

Government policy and financial support, promotion by business groups, strategic insights of the universities and colleges as well as social needs of big data professionals are the four aspects that influence the big data's deep development in higher education. Figure 2 shows the interaction mechanism between the big data and higher education.

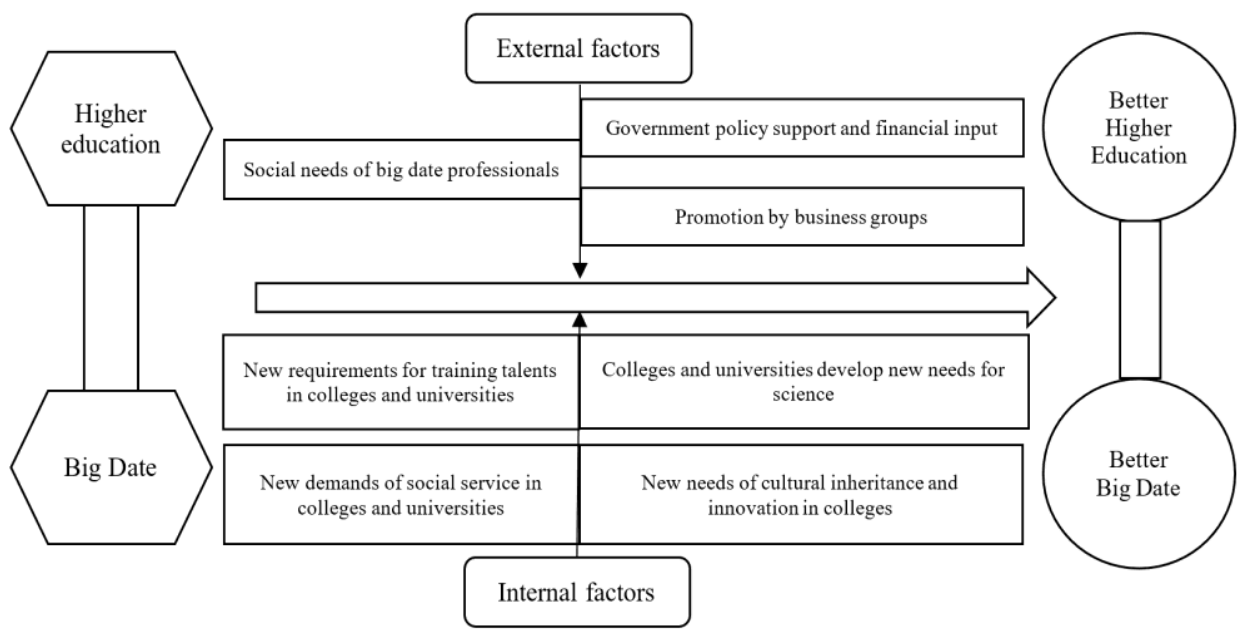

Figure 2. Mechanism of interaction between big data and higher education

Under the effect of both external and internal factors in the four aspects, the big data has developed further in college and university talents training, science research, social service and cultural heritage. Under the interaction mechanism between the big data and higher education, better big data and higher education will be produced (Lane, 2014). 


\section{The big data's impact on business administration education reform in teaching style}

\section{The teaching reform driven by the big data}

The application of the big data in the American higher education is used to analyze the propelling function of the big data in the university education reform, which can be divided mainly into three aspects: the learning behavior quantification, the individual education realization and teaching prediction fulfilment.

(1) Learning behavior quantification

Large-scale quantification of the learner behavior is the premise and foundation for observing the learning rule and determining the method to solve teaching problems. And the popular Massive Open Online Course (MOOC) is useful in collecting the big data. Currently there're mainly three open teaching platforms in America, Coursera, Udacity and edX. By May, 2015, over 13 million persons have registered on Coursera, over 3 million persons have registered on Udai city and over 1.5 million persons have registered on edX. Many universities have attracted students from around the world to learn online with the mode of open courses. The course Electric Circuit and Electronics opened by MIT in 2012 attracted during its 14-week duration over 150,000 students, double the population of the whole university. The teaching scale has also changed in terms of courses and varieties. By May, 2015, Coursera had already shared 1040 online courses from its partner universities covering the Natural Science, Social Science, and the Finance, etc. (Riffai, Duncan, Edgar \& AlBulushi, 2016).

(2) Individual education realization

In the era of popular education, in order to improve the education fairness, individual needs of students are always neglected, and the stereotyped teaching standard obstacles the improvement for students of different levels. Against the backdrop of the big data era, the individual education can meet learning demands of various individuals, thus realizing large-scale individualization (Daniel, 2015).

The "degree compass" individual course recommendation system is adopted by the Austin Peay State University (APSU). During course selection, the system will search for courses and match their relevance, then predict scores, and finally provide an individual course list for the students after comprehensive consideration of scores, professional demand, and course importance by combining the students' learning scores with the the score database of previous graduates.

(3) Teaching prediction fulfilment

The American Purdue University is a case of teaching intervention by the big data. Early in 2003 the Purdue early warning system (PAWS) was already established and later in 2007 a new system "Course Signals" was introduced. Currently over 6000 students and 145 teachers are using the new system which can detect potential risk of students lagging behind and then conduct a certain intervention (Johnes, 2006). 


\section{The learning reform driven by the big data}

The popularization of the data driving education and adaptive learning in the universities and colleges represents the combination of the big data and business administration education. Figure 3 is the flow chart of the big data based adaptive learning system.

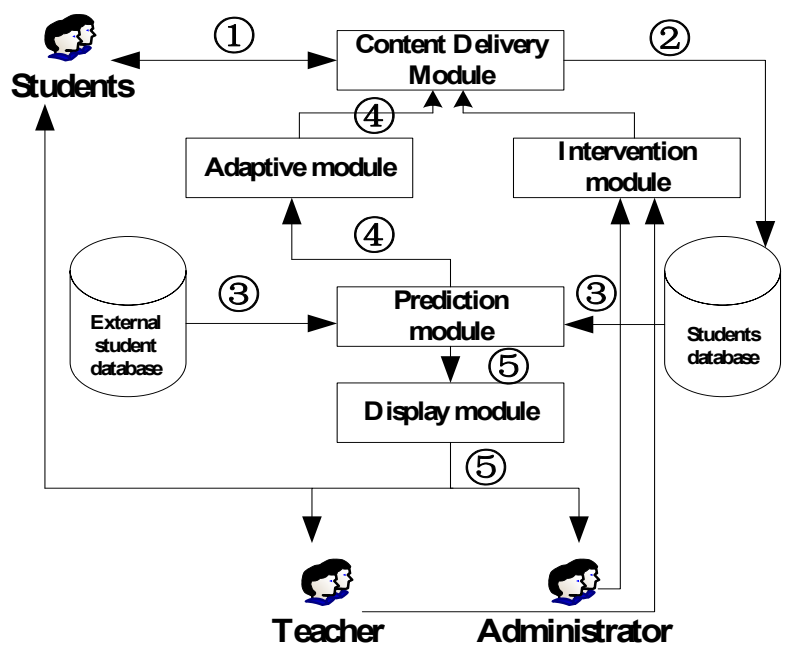

Figure 3. Big data based adaptive learning system structure and process

The case of learning support improvement based on the big data is from the Khan Academy, which has launched a visual learning dashboard that is able to monitor dynamically the login times, learning time and progress by the learners. With characteristics of integration, miniaturization and gamification, the dashboard can provide the students with high-quality efficient learning support. Its functions are mainly to provide the students with progressive learning support, i.e. from the intuitive Self-Awareness to Self-Reflection, then to Meaning Construction, and finally to the Impact on the learners and their learning progress.

The evaluation, management, scientific research and service reform driven by the big data

The evaluation reform driven by the big data. The big data spurs the evaluation reform in education mainly in three aspects: 1. promoting the development of formative evaluation: specifically, it means the transition of the education evaluation from empiricism to dataism, in which the big data covers the learning performance in every semester, every course and of every student, teaching experience of teachers, and complete teaching performance records of teachers. Overall and accurate education evaluation is also conducted to students and teachers with the computer science evaluation model. 2. Transforming the evaluation standards: the teaching evaluation standards, changing from storage developable to value-added type, focuses on future development and potential for growth of teaching rather than on the simple quantitative indicators such as learning scores or employment rate, etc. 3. Diversified evaluation: it helps teachers evaluate students' knowledge, capability and quality based on data instead of evaluating the teaching demand for the students based on experience and intuition as before. 
The management reform driven by the big data. The intensive fusion between the big data and the American education is promoting the multi-aspect reform in education management, which covers the application circumstances: integrating education data to discipline the management system; managing the data efficiently so as to improve administration management quality; monitoring the data to strengthen the Internet security; constructing basic infrastructure for data sharing.

The science research reform driven by the big data. Deeply applied in American education, the big data is spurring the science research reform in various aspects, the detailed application circumstances involve: accelerating the transformation of social science based on scientific innovation; usher into a new level of science research by spurring the birth of new subjects; grasping academic research trend for better level of science research

The service reform driven by the big data. The big data promotes the service reform in two major aspects: 1. exploiting the education data to optimize employment service 2. using the education data for optimization of the university selection service. This chapter will focus on the optimization of the university selection service. In order to obtain a better education environment and teaching quality, students and their parents always need choose a new university or college after finishing a certain learning phase, and in China it is vitally important to choose a suitable university or college for higher education after the college entrance examination. In America the "college scorecard" is an excellent university selection website developed by several organizations using the big data technique. On it the users can choose the university or college after inputting the preferred specialty, bachelor, quantity of students and SAT\& ACT scores.

\section{College scorecard}

\section{Harvard University}

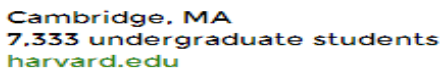

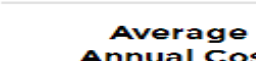

Average
Annual Cost

(i)

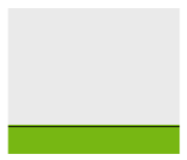

$\$ 17,882$

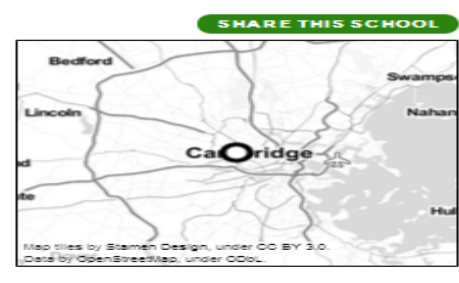

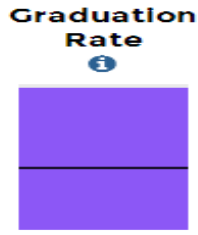

$98 \%$

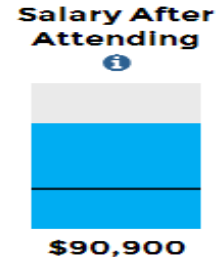

Figure 4. College scorecard score to Harvard University

Figure 4 shows the score of the Harvard University on scorecard, which also provides information about tuition fee, graduation rate, salary after attending, student's debt level, and employment rate, etc. in reference for college or university selection. 
Yang, Chen / Impact of Data Analysis on the Business Administration Education Reform in Teaching Style

In a word, the big data, deeply applied in various key fields of higher education such as teaching, learning, evaluation, management, science research and service, has broken through the operation mode of traditional education, broadened its function and improved its efficiency, thus providing guarantee for science innovation.

\section{Conclusions}

With the coming of the big data era, the big data technique is applied in various industries and its application in business administration education has become a research hotspot. This paper firstly introduces the theory about the big data and its application in business administration education, then analyzes the interaction relationship between the big data and business administration education, and finally studies the impact of the big data on business administration education reform in teaching style. Below is the major research and conclusions in this paper.

(1) The relation between the big data and business administration education is not a simple one that the big data is applied in the university education. Instead they are in a relationship of mutual promotion, restrain and synergic development.

(2) This paper refers to the application of the big data in the American education and studies the impact of the big data on the teaching style reform of business administration from the six aspects of reform in teaching, learning, evaluation, management, science research and service.

\section{References}

Brown, C., Thomas, H., Merwe, A. V. D., \& Dyk, L. V. (2008). The impact of south Africa's ICT infrastructure on higher education. Chemical Engineering Science, 8(2), 171-8.

Contributor, E. (2013). Emcvoice: Big data goes to school. Scientific American, 309(2), 51-3.

Costa, F. F. (2014). Big data in biomedicine. Drug Discovery Today, 19(4), 433-40.

Daniel, B. (2015). Big data and analytics in higher education: opportunities and challenges. British Journal of Educational Technology, 46(5), 904-920. http://dx.doi.org/10.1111/bjet.12230

Gupta, B., Goul, M., \& Dinter, B. (2015). Business intelligence and big data in higher education: status of a multi-year model curriculum development effort for business school undergraduates, MS graduates, and mbas. Communications of the Association for Information Systems, 36, 449-476. http://dx.doi.org/10.1016/b978-0-12-809198-2.00002-6

Gusev, A., Kashfullina, K., \& Nasonov, K. (2014). The reform of higher education in china and the republic of korea: application of international practices for modernization. Critical Care, 19(1), 1-10.

Johnes, J. (2006). Measuring teaching efficiency in higher education: an application of data envelopment analysis to economics graduates from UK universities 1993. European Journal of Operational Research, 174(1), 443-456. http://dx.doi.org/10.1016/j.ejor.2005.02.044

Kholin, Y. V., \& Kalugin, O. N. (2013). Training of specialists in chemistry at classical universities in the context of higher education reformation in Ukraine. Russian Journal of General Chemistry, 83(3), 586-593. http://dx.doi.org/10.1134/s1070363213030316 
$\overline{\text { Lane, J. E. E. (2014). Building a smarter university: Big data, innovation, and analytics. Critical issues in }}$ higher education. Suny Press.

Lazer, D., Kennedy, R., King, G., \& Vespignani, A. (2014). Big data. the parable of google flu: traps in big data analysis. Science, 343(6176), 1203.

Lu, R., Zhu, H., Liu, X., Liu, J. K., \& Shao, J. (2014). Toward efficient and privacy-preserving computing in big data era. IEEE Network, 28(4), 46-50. http://dx.doi.org/10.1109/mnet.2014.6863131

Peng, B. (2017). Construction and application of the best teaching mode of college English in big data. International Journal of Emerging Technologies in Learning, 12(9), 41. http://dx.doi.org/10.3991/ijet.v12i09.7483

Qin, S. J. (2014). Process data analytics in the era of big data. AICHE Journal, 60(9), 3092-3100. http://dx.doi.org/10.1002/aic.14524

Riffai, M. M. M. A., Duncan, P., Edgar, D., \& Al-Bulushi, A. H. (2016). The potential for big data to enhance the higher education sector in Oman. MEC International Conference on Big Data and Smart City, 1-6. http://dx.doi.org/10.1109/icbdsc.2016.7460346

Saude, S., Borralho, C., Feria, I., Lopes, S., \& Dziawgo, L. (2014). The impact of a higher education institution on socioeconomic development - The study case of the polytechnic institute of Beja, Portugal. Pharmacological Research, 3(2), 151. http://dx.doi.org/10.12775/cjfa.2014.024

Zhang, G., Li, J., \& Hao, L. (2015). Cloud computing and its application in big data processing of distance higher education. International Journal of Emerging Technologies in Learning, 10(8), 55. http://dx.doi.org/10.3991/ijet.v10i8.5280 